\title{
Erratum to: Tautomerism in acyl-pyrazolones and in a novel photolysis product - importance and impact of the accurate localization of hydrogen atoms in crystal structures
}

\author{
Lorraine A. Malaspina ${ }^{1}$ - Allan H. White ${ }^{2}$ - Dieter Wege ${ }^{2} \cdot$ Michael B. Tolmie $^{2}$. \\ Brian W. Skelton ${ }^{2} \cdot$ Simon Grabowsky ${ }^{1,2}$ (D)
}

(C) Springer Science+Business Media, LLC 2017

Erratum to: Struct Chem (2017) 28:1343-1357

https://doi.org/10.1007/s11224-017-1005-0

The original version of this article unfortunately contained a mistake that was introduced in the editing process. The layout of table 2 had been misleading and was adjusted.

The original article was corrected.

The online version of the original article can be found at http://doi.org/10. 1007/s11224-017-1005-0

\footnotetext{
Simon Grabowsky

simon.grabowsky@uni-bremen.de

1 Universität Bremen, Fachbereich 2, Biologie/Chemie, Institut für Anorganische Chemie und Kristallographie, Leobener Str. NW2, 28359 Bremen, Germany

2 The University of Western Australia, School of Molecular Sciences, M310, Perth, WA 6009, Australia
} 